\title{
Legitimidade e obediência \\ Diálogos da criminologia com a teoria sociológica
}

\author{
Ariadne Natal* \\ https://orcid.org/0000-0002-5925-043X \\ Frederico Castelo Branco** \\ https://orcid.org/0000-0001-8655-5792 \\ Marcos César Alvarez* * \\ https://orcid.org/0000-0001-5984-9082
}

A construção e a manutenção da legitimidade das instituições encarregadas de aplicação da lei são o mote de uma literatura que se tem desenvolvido nas últimas décadas, principalmente a partir dos anos 1990. Apesar de tal produção se situar majoritariamente no âmbito da Criminologia, o interesse pelo impacto da relação entre cidadãos e autoridades no funcionamento das agências encarregadas de aplicar as leis tem sido objeto da atenção de pesquisadores que se localizam em campos diversos, como a Psicologia Social, a Sociologia, a Ciência Política e o Direito.

A conceitualização e a operacionalização empírica da ideia de legitimidade seguem em debate até os dias atuais. $\mathrm{O}$ entendimento mais difundido é que a legitimidade pode ser observada principalmente por meio do compartilhamento entre cidadão e autoridades de um senso valorativo, moral e ético (alinhamento normativo) e de um senso de dever/obediência por parte daqueles a quem as ordens são direcionadas.

* Peace Research Institute Frankfurt, Alemanha.

** Universidade de São Paulo, São Paulo, Brasil.

1. Este texto é produto das discussões dos seminários “A questão da legitimidade na teoria social”, organizado entre 2017 e 2018 pelo Núcleo de Estudos da Violência da Universidade de São Paulo (NEV-USP), em parceria com o Laboratório de Pesquisa Social do Departamento de Sociologia da Universidade de São Paulo (Laps-UsP), sob coordenação do Prof. Dr. Marcos César Alvarez. Tais seminários integraram o Projeto "Building Democracy Daily: Human Rights, Violence, and Institutional Trust” na condição de Centro de Pesquisa, Inovação e Difusão com financiamento da Fundação de Amparo à Pesquisa do Estado de São Paulo (Cepid-Fapesp 2013-07923-7). As opiniões, hipóteses e conclusões ou recomendações expressas neste material são de responsabilidade do(s) autor(es) e não necessariamente refletem a visão da Fapesp. 
Embora os estudos tenham foco principalmente na legitimidade de instituições como a polícia e a justiça, permanece a referência a uma questão que é central para a teoria sociológica e para as ciências sociais em geral: "Por que as pessoas obedecem às autoridades, às instituições e aos governos?”.

Do ponto de vista dos governantes, é conhecida a concepção de que aqueles em posição de submissão obedecem ao poder dos dominantes por medo das consequências da desobediência (Maquiavel, [1532] 2010; Hobbes, [1651] 1974). No entanto, para além do medo, o processo de socialização e a estrutura do poder são fundamentais para viabilizar a dominação (La Boétie ([1542] 1982). Mais do que somente por medo, as autoridades devem contar com uma expectativa razoável de que seus comandos sejam acatados com base em certo reconhecimento do direito de exercer o poder.

E é em um quadro de intensas transformações sociais - que implicaram a perda de hegemonia das formas tradicionais de autoridade e o surgimento de formas mais impessoais e rotinizadas de exercício de poder nas sociedades ocidentais - que a reflexão sobre tal expectativa de reconhecimento do direito de exercer poder é desenvolvida de maneira seminal por Max Weber em Economia e sociedade ([1922] 1999). Preocupado com a reflexão acerca da estabilidade das relações de poder, o autor recorre ao conceito de legitimidade para pensar a preservação da autoridade em relações de dominação, ao apresentar uma reflexão ainda bastante influente nas Ciências Sociais acerca da compreensão das formas de exercício de poder e as condições em que as pessoas estariam dispostas a reconhecer uma autoridade e a obedecer a ela.

O presente artigo procura traçar as linhas gerais que articulam a leitura de Weber por autores que influenciaram diversas abordagens da noção da legitimidade no campo da Criminologia, incluindo debates a respeito de sua operacionalização e mensuração empírica. Para tal, na primeira parte do texto é apresentada, em linhas gerais, a proposta weberiana sobre a crença na legitimidade da autoridade. A seguir, a segunda parte traz discussões sobre os contornos e limites da concepção weberiana para pensar a legitimidade na contemporaneidade, assim como as proposições de Beetham (1991a) e Coicaud (2002) que apresentam uma concepção multidimensional da legitimidade e apontam elementos constitutivos que podem permitir sua operacionalização empírica. Na terceira parte, busca-se caracterizar o desenvolvimento da linha de estudos sobre legitimidade no campo da criminologia, sobretudo por meio dos estudos de Tom Tyler (2003, 2004, 2006a, 2006b), que se vale do conceito de legitimidade para investigar a disposição para a obediência de determinações das leis, autoridades judiciárias e policiais. Em seguida, conduzimos a discussão para o debate a respeito das possibilidades, obstáculos e limitações da mensuração empírica 
da legitimidade. Por fim, apresentamos uma solução de mensuração da legitimidade discutida e aplicada no contexto brasileiro.

\section{Legitimidade na sociologia weberiana}

O tema da legitimidade está presente tanto nas suas discussões sobre ordens sociais legítimas, quanto nas passagens sobre dominação. No entanto, para Spencer (1970) a ausência de uma discussão entre a abordagem da legitimidade na perspectiva da dominação/autoridade ${ }^{2} \mathrm{e}$ a abordagem das ordens legítimas é uma das dificuldades para entender como o tema é tratado por Weber. Uma possível explicação para essa ausência advém da natureza póstuma da obra e da trajetória editorial adotada por Marianne Weber, o que enseja até os dias de hoje um debate sobre a pertinência ou não de se tratar Economia e sociedade como uma obra coerentemente unitária (Pierucci, 2008).

Quanto à ordem legítima, essa diz respeito a um sistema normativo que orienta as condutas dos indivíduos ${ }^{3}$, tanto por meio de mecanismos internos aos atores quando movidos por orientações subjetivas -, quanto por mecanismos externos a eles - que operam por meio de orientações extrínsecas, limitando as escolhas e alternativas dos indivíduos. Destarte, as bases de sustentação de uma ordem legítima não podem estar ancoradas apenas em razões utilitárias, assentadas em fatores externos aos indivíduos. Assim, a vigência legítima de uma ordem repousa principalmente em um sentimento de dever e de submissão, cujos fundamentos podem estar calcados no costume, no afeto (e inclinações pessoais), na legalidade das leis ou ainda ser motivada por razões valorativas, normativas e ideais (Weber, 1999a).

Nesse sentido, uma ordem legítima vigente é aquela que orienta condutas e ações sociais dos atores por meio de normas cuja violação provocaria não só possíveis sanções, mas, principalmente, a violação de um sentimento de dever. Desse modo, quando uma determinada ordem social é vista como legítima e mandatória, aumentam as chances de os atores regularem suas condutas de acordo com ela. Destarte, as ordens legítimas seriam meios mais estáveis para regular condutas (Weber, 1999a; Spencer, 1970).

2. O termo original Herrschaft foi traduzido nas versões brasileiras das obras de Weber como dominação. Entretanto, como é um termo polissêmico, há um debate a respeito de qual o sentido mais adequado para seu uso. A ideia de dominação parece adequada quando se trata das formas tradicionais, mas, ao pensarmos na burocracia moderna, a palavra autoridade parece fazer mais sentido (Beetham, 1991b e Kalberg, 2005). Por isso, não é raro que a tradução de Herrschaft oscile entre dominação e autoridade.

3. Importante destacar que, para Weber, não há necessariamente uma única ordem operando. Na realidade, não raras vezes, múltiplas ordens paralelas e contraditórias podem orientar as ações dos sujeitos ao mesmo tempo. Assim, cada ordem social é válida na medida em que efetivamente tem a capacidade de orientar as ações dos envolvidos. 
Quanto à dominação, Weber entende que todas as esferas de ação social são influenciadas por estruturas de dominação caracterizadas por vínculos que envolvem os indivíduos em relações de mando e de obediência. No caso, a legitimidade é acionada como estratégia para diferenciar a dominação e as formas de dominação legítima do mero exercício de poder. Especificamente sobre o poder, Weber entende ser essa uma categoria muito abrangente e de difícil exploração analítica ${ }^{4}$, uma vez que há muitas situações em que uma pessoa pode estar em posição de exercer poder sobre outra (ou seja, em posição de impor a própria vontade ao comportamento de terceiros, mesmo diante de resistências). No entanto a dominação legítima denotaria um caso especial de poder, pois não se trata de impor a própria vontade, mas de um mandato que é obedecido voluntariamente (Weber, 1999a).

Assim como o poder, a dominação pode ocorrer de diversas formas nas relações sociais. De maneira geral, para Weber existiriam dois tipos diferentes de dominação: em virtude de interesses e em virtude da autoridade. Quando repousa apenas em mecanismos externos, baseados em motivações instrumentais, a dominação seria menos estável. Ainda que uma relação de dominação possa se manter por meio de mecanismos de submissão externos aos sujeitos, como por meio do recurso à coerção, a relação daí decorrente tende a ser mais instável e custosa.

Para garantir que o sentido não se perca e que o conceito seja analiticamente relevante, Weber delimita sua definição sociológica optando, metodologicamente, por não se estender sobre a dominação que ocorre por razões instrumentais. Assim, centra a atenção na dominação em virtude da legitimidade, como aquela que envolve sempre uma consideração da obediência voluntária.

Se "todas as formas de dominação procuram 'despertar e cultivar a crença em sua legitimidade"” (Weber, 1999, v. 1, p. 139), essa última seria fruto de um processo dinâmico que precisaria ser cultivado continuamente na relação entre dominantes e dominados. Nesse sentido, as formas mais estáveis de dominação são aquelas em que as condutas são orientadas por razões valorativas, ou seja, fundadas em uma crença na legitimidade daqueles que detêm o poder. Assim, a legitimidade diz respeito à crença na validade da dominação e ao reconhecimento da reivindicação do direito de exercer poder, o que significa que tanto a justificativa para o poder, quanto a estrutura de dominação precisam ser consideradas socialmente válidas por aqueles que estão submetidos (Beetham, 1991b; Netelenbos, 2016).

A partir de uma perspectiva empírica - com base naquilo que é aceito como relevante pelos agentes dentro de seu próprio contexto -, Weber ressalta que todo exercício de dominação carece de justificação. Mesmo em situações mais corriqueiras

4. Weber (1999b) entende que a categoria poder seria sociologicamente amorfa. 
da vida social, quando há contrastes muito acentuados entre as partes envolvidas em uma relação de poder, aquele que se encontra em posição favorável sente a necessidade de justificar seu privilégio como legítimo e sua situação como merecida. No processo de justificação, as autoridades procuram se convencer de seu direito ao poder e fomentar nos subordinados a percepção de que esse direito é merecido e não arbitrário. Quando bem-sucedidas, as autoridades poderão contar com a disposição a obedecer, o que assegura a posição de maneira muito mais eficaz do que o emprego da coerção (Kalberg, 2005).

Para a dominação no sentido weberiano, não basta que a ordem seja acatada. É preciso que ela seja recebida pelos dominados como uma norma válida, quer dizer, ser crível em sua validade. A recepção do conteúdo do mandato por parte do dominado é o que distingue poder e dominação, pois não se trata apenas de impor a própria vontade e garantir obediência, mas sim de um mandato a ser obedecido em razão do reconhecimento, em alguma medida, de sua validade.

Com base nisso, Weber analisa diversos processos de legitimação investigando como os sentimentos de dever dos subordinados surgem e são cultivados 5 . E a partir daí estabelece sua conhecida tipologia de dominação, na qual os princípios de legitimação estão calcados nas crenças a respeito da validade de três tipos de dominação: a) dominação legal, que envolve a crença em um sistema de leis, regras e normas; b) dominação carismática, com a crença na revelação e nas qualidades extraordinárias da autoridade; e c) dominação tradicional, sobre a crença nos costumes e na santidade das tradições (Weber, 1999a).

Mas afinal de contas, como a legitimidade das ordens e a da dominação se conectam em Weber? Spencer (1970) entende que ambas lidam com diferentes aspectos de um mesmo fenômeno: as formas que fundamentam todas as instâncias de interação humana ordenada. A interação humana ocorre quando, em um determinado contexto, há uma probabilidade de que um significativo número de atores orientará suas ações de acordo com as mesmas normas. A partir disso, Spencer entende que Weber diferencia ordens (sistemas normativos) e dominação (autoridade) da seguinte maneira: enquanto a norma se refere às regras de conduta diante das quais os indivíduos orientam seus comportamentos, a autoridade trata da relação de comando e obediência que se estabelece entre dominantes e dominados, quando comandos de uns são recebidos como mandatórios/obrigatórios por outros. Para Spencer, normas e autoridade indicam princípios polares da organização social: as normas orientam para uma regra ou um princípio; a autoridade indica a conformidade aos comandos.

5. Aqui, cumpre marcar a distinção entre legitimação, isto é, ações e processos que conferem legitimidade; e a legitimidade em si, crença subjetiva no direito de exercício de poder (Netelenbos, 2016). 


\section{Perspectiva contemporânea}

O tema da legitimidade torna-se mais premente no contexto de ascensão de regimes democráticos, quando a manutenção do poder pelas justificativas que remetem à tradição ou ao direito divino fica em segundo plano. A ampliação do direito de cidadania e o advento de novos modelos representativos implicam alterações no processo de legitimação das lideranças políticas e nas diretrizes de organização e funcionamento do Estado. Trata-se de sistemas que requerem consentimento expresso daqueles que se submetem, o que envolve a necessidade de um consenso básico dos cidadãos (Faria, 1978).

Se, por um lado, a garantia da ordem, proteção, segurança e condições para a cooperação são os elementos que dão ensejo à fundação do Estado e justificam a concentração de poder nas mãos de algumas pessoas com a prerrogativa de exercerem poder sobre outras, por outro lado, é preciso garantir que a solução não se torne também um problema, ou seja, evitar que o Estado avance além de seus limites e, ao invés de promover segurança, passe a promover o terror. A existência de legitimidade seria uma expressão de equilíbrio ante esse dilema, uma vez que o poder legítimo é aquele que é explicado, justificado e expressamente aceito (Williams, 2005).

Em sociedades democráticas contemporâneas, a necessidade de legitimidade se torna um imperativo justamente quando o "outro", aquele que é submetido à relação de poder, passa a ser considerado como um fator importante na equação. É justamente quando os submetidos se convertem em agentes de direitos que a reciprocidade nas relações de poder é reforçada e seus interesses passam a ser considerados, maximizando as cobranças sobre como o poder é exercido (Coicaud, 2002). Por essa razão, é preciso garantir não só mecanismos capazes de manter a crença no ordenamento jurídico e nas instituições políticas, como também satisfazer, ao menos em parte, as necessidades e expectativas por meio de um alinhamento mínimo de valores acordados entre os grupos sociais envolvidos e as estruturas institucionais de autoridade existentes (Faria, 1978).

Como já mencionado, mesmo para Weber, as bases da legitimação e os fundamentos que justificam o exercício do poder devem ser considerados a partir do ponto de vista empírico, levando em conta o que é tido como válido pelos agentes envolvidos na relação. Williams (2005) afirma que as justificativas para a legitimidade não são universais, mas sim contextuais e variam muito no tempo e no espaço. Aquilo que é considerado legítimo precisa fazer sentido como justificativa tanto para os que exercem a autoridade, quanto para os que estão subordinados, dentro de um determinado contexto histórico, social e cultural. Assim, o que é considerado legítimo, aqui e agora, é o que, aqui e agora, faz sentido como legitimação do poder da autoridade.

Para David Beetham (1991a), é muito difundida entre diversos cientistas sociais uma leitura simplista de Weber, que limita a fundamentação da legitimidade em sua 
obra a uma questão de crença, desconsiderando aspectos fundamentais, concernentes ao modo como as relações de poder são efetivamente exercidas e, principalmente, deixando de lado a sua relação com valores sociais. Quando os pesquisadores focam na crença na legitimidade sem levar em conta as motivações e fundamentos que lhes são subjacentes e lhes garantem sustentação, terão dificuldades para explicar variações e indicar o que torna um poder legítimo em um determinado contexto e não em outro.

Em The legitimation of power (1991a), Beetham critica essas construções e sustenta que uma relação de poder não é legítima porque as pessoas acreditam em sua legitimidade, mas porque pode ela ser justificada em termos de suas crenças. Por consequência, vislumbra uma abordagem alternativa, que parte de uma perspectiva multidimensional, que se pretende universal com relação à forma, mas que ao mesmo tempo permita considerar as variações contextuais e históricas, ensejando inclusive comparações e a possibilidade de pensarmos em graus de legitimidade - e não apenas sua presença ou ausência (Beetham, 1991a, 2011 e 2013a).

Na perspectiva do autor, a primeira dimensão dessa abordagem de legitimidade é a forma como o poder é adquirido. O exercício do poder deve ocorrer em consonância com o convencionado e, muitas vezes, é independente das crenças das pessoas. Esse seria um requisito de legalidade, que, vale frisar, não é necessariamente formal (pode ser informal, convencional ou não convencional). Um segundo requisito seria o consentimento, ou seja, a expressão por meio de ações que demonstrem a concordância com aquela relação de poder.

As regras, por sua vez, devem ser sustentadas por princípios normativos que as fundamentem, ou seja, a legalidade enseja uma justificação. Isso significa que as regras de poder devem ser justificáveis de acordo com as crenças socialmente compartilhadas, tanto a respeito da fonte legítima de autoridade, isto é, quem está qualificado para exercer o poder e como é designado, quanto a respeito dos fins ou propósitos apropriados para o poder e suas formas de exercício. De tal modo as posições de autoridade são publicamente reconhecidas e consentidas pelos subordinados por meio de ações que confirmam sua aceitação e reconhecimento.

Legalidade, consentimento e justificação normativa (crenças compartilhadas) ${ }^{6}$, juntos, oferecem ao subordinado os fundamentos morais para cumprimento, coope-

6. Cada uma dessas dimensões da legitimidade pode ser pensada a partir de seu caráter negativo: (a) Ilegitimidade: poder adquirido ou exercido em desacordo com as leis e normas (como, por exemplo, Golpe de Estado); (b) déficit de legitimidade: falta de lastro social da justificação normativa, ocorre quando regras se distanciam das crenças compartilhadas ou são contestadas e geram questionamentos a respeito do direito da autoridade em exercer o poder (como, por exemplo, movimentos separatistas); e (c) deslegitimação: declínio do consentimento e do reconhecimento público (como, por exemplo, uma grande mobilização e oposição pública a um regime, movimentos revolucionários etc.) 
ração e obediência à autoridade ${ }^{7}$. Embora a substância da legitimidade - aquilo que é efetivamente aceito como relevante pelos agentes inseridos na relação de poder - seja composta por elementos contextuais que podem variar de acordo com a conjuntura, haveria, segundo Beetham (1991a), um arcabouço necessário para a existência da legitimidade, que por sua vez seria comum a todos os sistemas de poder legítimos. Para o autor, quando essas três dimensões estão presentes, não dizemos que há uma crença na legitimidade do poder, mas que o poder é legitimado naquele contexto.

Jean-Marc Coicaud (2002), em Legitimacy and politics: A contribution to the study of political right and political responsibility ${ }^{8}$, parte de uma definição minimalista de legitimidade, que apresenta como "o reconhecimento do direito de governar". Entretanto, tal qual Beetham (1991a), ele também compreende a legitimidade como um constructo multidimensional. De início, destaca o consentimento como um fundamento central da constituição da autoridade que se pretende legítima, na medida em que a identificação do poder com o direito só existe enquanto o consentimento existir. Outro ponto é a importância das normas e valores, uma vez que é esperado que aqueles que comandam e aqueles que obedecem estejam alinhados quanto aos valores que a política objetiva promover. E, em terceiro lugar, Coicaud ressalta a legalidade, entendida como conformidade da lei com os interesses da sociedade. Enquanto os valores fundamentais do grupo e o consentimento dos indivíduos determinam a base da origem do poder, a lei, assim entendida, estabelece as condições precisas para o seu efetivo exercício no âmbito de um relacionamento do direito. Nesse sentido, a lei legítima delimita de maneira concreta os direitos e deveres. Tais limites não devem ser excedidos, de modo a se cristalizarem como uma regra que está acima dos governantes e dos governados, diferentemente do poder nu, baseado somente na força.

Em artigo no qual resgatam os fundamentos teóricos da legitimidade, tal como abordada pelos estudos no campo da criminologia, Bottoms e Tankebe (2012) destacam que os trabalhos de Beetham e Coicaud têm poucos anos de diferença e chegam a conclusões próximas quanto à multidimensionalidade do conceito de legitimidade. De acordo com os autores, tanto a definição do fenômeno quanto sua observação empírica guardam um aspecto que precisa ser tratado com mais atenção por esta

7. Os três elementos apontados por Beetham (1991a) como partes da legitimidade se baseiam nos três tipos de dominação weberiana. A crítica é que a classificação weberiana separa, em tipos de legitimidade distintas, elementos que na realidade seriam constituintes e complementares ao conceito de legitimidade: a) a legalidade se fundamenta na dominação racional-legal e na importância das regras; b) as crenças compartilhadas se pautam na dominação tradicional e no apreço pelos valores; e c) o processo de legitimação por consentimento se baseia na dominação carismática e na disposição de seguir o líder.

8. A publicação em inglês em 2002 é precedida pela publicação em francês datada de 1997 - Légitimité et politique (Presses Universitaires de France). 
literatura: a perspectiva de quem está submetido na relação de poder. Isso porque defendem que a legitimidade seria fruto de um processo dinâmico, que precisa ser cultivado em uma relação contínua, uma espécie de diálogo que envolve os detentores do poder e os cidadãos. Aqueles que detêm ou buscam o poder fazem uma reivindicação a respeito do direito de governar, e a população responde a essa reivindicação. A reivindicação e seu teor podem se ajustar ao público e às suas respostas, em um processo contínuo, uma dinâmica que permeia tanto as relações com autoridades de alto escalão, quanto com aquelas que atuam na ponta, no cotidiano das ruas.

Evidente que em sociedades complexas, cujo tecido é permeado por diferentes grupos de interesse, podem existir diferentes concepções entre a população e com os detentores do poder a respeito do papel de cada acerca de quais princípios e valores devem orientar as ações e condutas. São justamente o diálogo e o debate que modulam esses atores em busca de um terreno comum. Por essa razão, a legitimidade não pode ser vista como algo estático e único, mas como fruto de um exercício dialógico e relacional constante e interativo que envolve reivindicações e respostas (Bottoms \& Tankebe, 2012).

\section{A questão da legitimidade da Criminologia}

A concepção de que o consentimento, a justificação baseada em valores e a legalidade consistem em elementos-chave para observar a legitimidade (Beetham, 1991a; Coicaud, 2002), a seu modo, se mostra presente nas pesquisas empíricas relativas à legitimidade de instituições como a polícia e o judiciário, que têm ocupado lugar de destaque na pesquisa criminológica nas últimas três décadas.

$\mathrm{Na}$ Criminologia, a questão da legitimidade se configura em um objeto de interesse por fornecer elementos para investigar os mecanismos que motivam as pessoas a obedecerem às leis e autoridades, com foco nos agentes de aplicação da lei. O tema se tornou objeto da disciplina em meados dos anos 1990, a partir das pesquisas de Tom R. Tyler, que, baseado em Weber, também aponta uma distinção entre abordagens instrumentais e valorativas para as motivações que levam à obediência. $\mathrm{O}$ autor parte de uma crítica à perspectiva instrumental, apontando que este tem sido o modelo preponderante para públicas de segurança e justiça em diversos países ocidentais, apresentando então um modelo de regulação alternativo, baseado em procedural justice (Tyler, 2006a).

Tal abordagem instrumental de controle social parte do pressuposto de que seres humanos agem baseados em expectativas sobre as consequências (custos e benefícios) de suas ações, de maneira que tanto obedecer quanto violar as leis seriam comportamentos condicionados a um cálculo utilitário a respeito dos prováveis ganhos e 
perdas deles derivados. Dessa maneira, os indivíduos estariam mais inclinados a cometer transgressões quando percebem que os ganhos decorrentes de uma violação são maiores do que os eventuais riscos de serem pegos e punidos ${ }^{9}$. Tal lógica racional se combina com a teoria da dissuasão (Deterrence Theory) ${ }^{10}$, uma das teses que mais influenciaram a Criminologia no século xx. Segundo ela, o principal mecanismo que impede crimes e transgressões é o receio da penalidade. Por conseguinte, medidas como sanções e punições seriam estratégias eficazes para conformar ações, dissuadindo comportamentos indesejados e prevenindo crimes. Outra premissa dessa abordagem é de que o sistema de justiça criminal não existe apenas para identificar e punir aqueles que cometem violações, mas também para comunicar ao restante da sociedade sobre os riscos de punição se infringirem as normas.

No campo da segurança e da justiça criminal, tal perspectiva teve considerável adesão de autoridades políticas e membros das instituições de lei e ordem, com consequente impacto em políticas públicas que se focam prioritariamente em soluções punitivas e dissuasórias como estratégia para desestimular o desrespeito às leis. Mencionamos especialmente aquelas que buscam aumentar a certeza e a severidade da punição, como investimento em policiamento ostensivo, vigilância, endurecimento penal e criminalização de condutas, resultando em encarceramento em massa, que ocorreu a partir da década de 1980 nos Estados Unidos e, a partir dos anos 1990, no Brasil (Zanetic et al., 2016).

Já de acordo com o modelo valorativo de regulação, as decisões sobre obedecer ou não às leis seriam influenciadas, predominantemente, pelo que os indivíduos consideram certo, moral e justo, e não apenas por interesses relacionados a perdas

9. Tal abordagem tem forte influência da perspectiva econômica da escolha racional e ganhou musculatura na Criminologia em meados dos anos 1960, por meio de pesquisas que buscam testar empiricamente tais pressupostos (Becker, 1968, e Gibbs, 1968, apud Paternoster, 2010). A escolha racional pressupõe que as ações humanas são orientadas por sua utilidade esperada, o que ajudaria a explicar diversos comportamentos, inclusive a disposição a cometer crimes. A decisão de delinquir seria tomada em situações nas quais existem oportunidades e ganhos que superam os riscos e custos prováveis em curto ou longo prazo, ou seja, as pessoas violariam as normas quando a expectativa de retorno é maior do que o custo-benefício de seguir a lei.

10. Os conceitos subjacentes à perspectiva instrumental remontam principalmente a Cesare Beccaria ([1764] 2016), que defende a certeza da punição como estratégia para a dissuasão criminal, e a Jeremy Bentham ([1871] 1996), que defende que as ações dos indivíduos são motivadas por interesses individuais de maximizar prazeres (benefícios) e minimizar o sofrimento (custos), de maneira que um bom sistema de punição é aquele capaz de influenciar tal julgamento. Embora desenvolvidos no século xviii, esses trabalhos foram pouco influentes durante os séculos seguintes, visto que nesse período o foco principal dos estudos criminológicos foram modelos positivistas biológicos e psicológicos que entendiam o comportamento criminal como resultado de patologias da mente do indivíduo delinquente, e não como resultado de contextos políticos ou sociais. Essa abordagem foi retomada em meados da década de 1960, com a influência da teoria da escolha racional. 
e recompensas pessoais. Nesse sentido, quando entendem que respeitar as leis é o mais apropriado a se fazer, as pessoas estariam mais propensas a assumir essa obrigação e tenderiam a se comprometer com o cumprimento das regras, independentemente de quais são os incentivos e riscos associados a essa adesão. Dentro de tal perspectiva, Tyler (2006b) traça uma distinção entre as motivações para obedecer relacionadas à moralidade pessoal (um julgamento pessoal a respeito do que é justo ou injusto $)^{11}$ e a motivação para obedecer baseada na legitimidade, que significa obedecer à lei por reconhecer que a autoridade que a aplica tem o direito de prescrever comportamentos. Embora tanto a moralidade quanto a legitimidade sejam entendidas como razões normativas, elas possuiriam motivações distintas. A legitimidade seria mais eficaz em promover o respeito às leis e às autoridades, pois essa decisão não passa por uma avaliação de ordem pessoal, ao passo que a moralidade individual pode tanto incentivar o respeito às leis e às autoridades, quanto levar à oposição a elas ${ }^{12}$.

Sob o ponto de vista das autoridades, a obediência voluntária, não instrumental e baseada na legitimidade, é mais vantajosa e menos custosa, uma vez que ela minimiza a necessidade de recorrer à ameaça ao emprego recorrente da força, o que implica menos dispêndio de recursos tanto materiais, quanto em termos de capital político. Em uma democracia, os detentores do poder necessitam que as pessoas aceitem suas decisões e respeitem a lei não porque se sentem ameaçadas, mas porque sentem que é a coisa certa a se fazer. Ainda que as autoridades muitas vezes tenham o recurso da força como uma possibilidade, evocar constantemente esse mecanismo para a manutenção da ordem é uma estratégia contraproducente e insustentável em longo prazo. Por essa razão, seria mais prudente contar com larga obediência voluntária e recorrer à força em situações muito estritas, apenas naquelas em que o respeito à lei é mais difícil de ser obtido.

Com tal premissa, Tyler desenvolve uma agenda de pesquisas voltada para explorar caminhos alternativos ao modelo de regulação baseado em recursos coercitivos, com foco na testagem de modelos empíricos e na realização de estudos aplicados que,

11. A questão da internalização de normas e de determinações é um tema clássico das ciências sociais, que foi abordado por nomes como Freud e Durkheim. No entanto, a abordagem de Tyler se diferencia dessas pois, para ele, a internalização do dever de obedecer não se baseia nos princípios de moralidade pessoal; pelo contrário, quando legitimam uma autoridade, os indivíduos estariam dispostos a suspender suas considerações morais e interesses pessoais, na medida em que concedem à autoridade o poder de determinar o comportamento adequado.

12. Principalmente em situações nas quais as leis e as autoridades indicam caminhos que não se alinham com a moralidade individual de parte da população. Tais situações se tornam evidentes especialmente diante de questóes polêmicas que dividem a sociedade, como, por exemplo, no caso da lei do aborto, de uso de drogas ou da convocação para uma guerra. 
posteriormente, inclusive se converteram em políticas públicas nos Estados Unidos, especialmente no que tange a ações policiais ${ }^{13}$.

A partir dessa construção, Tyler se dispõe a investigar o que é a legitimidade, como ela pode ser empiricamente observada e, principalmente, quais são os fatores que influenciam seu estabelecimento e consolidação. Para o autor, a legitimidade é encarada como um atributo das autoridades (pessoas, instituições ou leis) que leva os demais a sentirem o dever de se submeterem voluntariamente e seguirem suas determinações (Sunshine \& Tyler, 2003; Tyler, 2003). Essa leitura é próxima da proposição de Beetham (1991a) e Coicaud (2002), autores que reconhecem na legitimidade uma particularidade que confere à autoridade o direito ao exercício do poder e apontam para o dever de obedecer como sinal de reconhecimento dessa prerrogativa pelos governados.

Em linhas gerais, a operacionalização empírica que a literatura criminológica faz da noção de legitimidade para pensar principalmente a autoridade policial passa por observar o nível de consentimento dos indivíduos acerca da posse e do exercício do poder, sendo este resultado de certo alinhamento entre cidadãos e policiais a respeito das normas/valores que guiam e são protegidas pela atividade da autoridade. A ideia de consentimento é importante pois qualifica a obediência esperada em uma relação legítima e a distingue de outros tipos de obediência, como a obediência por convenção, impulso, ou mesmo por medo de sanção e/ou coerção. Mais do que somente um ato de voluntariedade, a obediência indica um reconhecimento público por parte do subordinado (Beetham, 1991a), assim como revela um mecanismo de reciprocidade, uma vez que, caso não haja reconhecimento da validade do direito de emanar ordens, não existe um caráter propriamente de direito (Coicaud, 2002).

Essas ideias refletem o esforço empírico do campo que, a partir de pesquisas quantitativas com dados coletados por meio de surveys, busca medir o conceito de legitimidade por meio de questões que tratam da percepção da obrigação de obedecer à autoridade - como, por exemplo, através de perguntas que colocam se o respondente entende que "as pessoas devem obedecer à polícia (ou às leis) mesmo que ela(s) contrarie(m) o que eles acham que é certo" (Tyler, 2006b).

Além da obediência, a confiança também aparece como um elemento que compõe a legitimidade, cumprindo o papel de uma avaliação geral do desempenho da autoridade, indicando que elas são confiáveis, honestas e minimamente atentas ao bem-estar das pessoas com quem lidam (Tyler, 2006a, 2006b; Tyler \& Huo, 2002).

13. Em decorrência das manifestações ocorridas em Ferguson, Missouri, após o assassinato do jovem Michael Brown por um policial local, o presidente norte-americano Barack Obama criou uma força tarefa em dezembro de 2014 (President's Task Force on 21st Century Policing) que, em 2015, publicou relatório com diversas recomendações, dentre as quais se destaca a temática "Construindo a confiança e legitimidade". 
Também compõe a noção de legitimidade nestes estudos a ideia de alinhamento normativo, que, por sua vez, sinaliza em que medida as instituições e autoridades são consideradas representativas de valores, estruturas normativas, morais e éticas particulares, justificando o exercício de poder pela autoridade por meio do compartilhamento de um propósito de coprodução da ordem social (Hough et al., 2010; Jackson et al., 2012a; 2012b).

A partir da definição e operacionalização da legitimidade, Tyler busca responder então qual é o mecanismo que torna as autoridades legítimas. Seus estudos (Sunshine; Tyler, 2003; Tyler, 2003, 2004; Tyler; Fagan, 2010), apoiados por outros tantos (Hough et al., 2010; Hough, Jackson \& Bradford, 2012; Oliveira, Zanetic \& Natal, 2020; Walters \& Bolger, 2019; Wolfe et al., 2016), apontam que as autoridades e instituições são vistas como legítimas quando exercem a autoridade por meio de procedimentos que as pessoas consideram justos (o que ele chama de procedural justice). Quando têm a experiência de procedimentos justos, os indivíduos ficariam mais propensos a aceitar decisões e regras, tenderiam a se comprometer e cooperar para o sucesso das instituições e autoridades.

Os resultados dessas pesquisas empíricas indicam que as pessoas estarão mais propensas a respeitar as decisões e cooperar com os detentores do poder, se sentirem que são tratadas com imparcialidade e atenção por autoridades confiáveis e dispostas a considerar seus pontos de vista. Ou seja, as autoridades conquistam o direito de serem obedecidas quando agem de maneira justa. Isso significa que a produção e a manutenção da legitimidade estão articuladas à forma como as autoridades exercem seu papel e à percepção de que elas são justas tanto no trato cotidiano, bem como no que diz respeito às avaliações mais gerais a respeito de seu papel institucional ${ }^{14}$. A legitimidade geraria um ciclo positivo para as autoridades, pois, quando as pessoas as consideram legítimas, estarão mais propensas a cooperar, facilitando as interações, aumentando ainda mais sua legitimidade. O contrário também seria verdadeiro, quando as pessoas veem as autoridades agindo de maneira injusta (ações corruptas, discriminatórias, abusivas ou violentas), estarão menos propensas a cooperar, tornando as relações mais tensas, resultando em decréscimo de legitimidade.

Em suma, o principal argumento de Tyler é que o caminho mais eficiente para fomentar o respeito às leis e autoridades não se dá pelo medo e pela punição, mas depende da forma como as autoridades agem e se apresentam, como tratam os subordinados e como investem seus recursos (Tyler, 2006b).

14. Embora a pesquisa de Tyler coloque o Procedural Justice como elemento central, ele reconhece que este não é o único fator que influencia a legitimidade, elementos como legalidade, eficiência e distribuição justa de recursos também são fatores concomitantes, mas com menor peso para o estabelecimento e a manutenção da legitimidade. 
As principais críticas à construção de Tyler e aos seus modelos empíricos de observação são propostas por Bottoms e Tankebe (2012), que se debruçam sobre as fundações teóricas e o constructo empírico de legitimidade. O principal questionamento levantado é em que medida o sentimento de dever obedecer a diretivas de uma autoridade efetivamente reflete a legitimidade. Os autores argumentam que, nas pesquisas do tipo quantitativas, há uma considerável dificuldade em diferenciar a obediência à autoridade que ocorre por razões instrumentais (o medo, o peso da obrigação, o sentimento de impotência diante das autoridades, a tradição, ou mesmo a ausência de alternativa), da obediência que é motivada pelo reconhecimento da legitimidade. Nesse sentido, a ideia de dever/obrigação não resolve as respostas geradas por apatia, tradição, aquiescência pragmática e cálculos instrumentais, e isso se coloca como uma das principais necessidades que as pesquisas sobre legitimidade precisam desenredar (Bottoms \& Tankebe, 2012; Tankebe, 2013).

Partindo dessa crítica, Tankebe sugere uma reconfiguração do indicador de legitimidade. Ele argumenta que a avaliação a respeito da forma como as autoridades agem não depende de variáveis independentes, que explicam a presença da legitimidade, mas sim de fatores constitutivos dela. Dessa forma, o autor propõe um indicador de legitimidade que é composto por aspectos como qualidade do processo decisório (tratamento respeitoso, honestidade, imparcialidade, disposição a reconhecer e corrigir erros), alocação justa de recursos (distribuição igualitária independente de grupos de interesse), eficiência na entrega de resultados (capacidade de a autoridade exercer o que se espera dela, por meio de um desempenho satisfatório) e legalidade (poder adquirido e exercido de acordo com regras estabelecidas em dada sociedade) (Tankebe, 2008; 2013; Bottoms \& Tankebe, 2012).

Tal crítica, adotada posteriormente por Sun et al. (2017), foi rebatida por Jackson e Bradford (2019), que defendem a construção empírica de legitimidade realizada por Tyler, focada na relação que os subordinados estabelecem com as autoridades. Eles argumentam que é importante evitar a imposição a priori a respeito de quais são as precondições e valores que tornam uma autoridade legítima. Nesse sentido, criticam a proposta de Sun et al. (2017) e Tankebe (2013), pois creem que se trata de uma concepção normativa de legitimidade, que impõe externamente e de cima para baixo quais critérios são válidos para julgar a legitimidade institucional, tratando-os ainda como valores universais.

Tal abordagem normativa também tem como consequência inviabilizar as explorações a respeito de quais componentes são mais relevantes em cada contexto, impondo limitações para que outros julgamentos e variáveis sejam considerados em se tratando da adequação normativa da atividade da autoridade. Assim Jackson e Bradford (2019) defendem que a legitimidade deva ser conceituada e medida 
como algo distinto dos julgamentos sobre justiça (procedimental e distributiva), eficácia e legalidade, inclusive porque precisamos avaliar quais desses elementos são mais importantes como preditores de legitimidade em cada contexto ou para cada agrupamento social, tornando inclusive a estratégia de mensuração empírica mais compreensiva quanto a diferenças culturais.

\section{Notas finais}

O debate sobre a conceituação e a mensuração da legitimidade segue acontecendo (Sun et al., 2018; Jackson \& Bradford, 2019; Cao \& Graham, 2019; Trinkner, 2019). Como reportado nas seçôes anteriores, apesar de sua relevância, a legitimidade ainda é um conceito desafiador enquanto categoria de trabalho, especialmente no delineamento e na aplicação de pesquisas empíricas.

No Brasil, o tema da legitimidade de instituições de segurança e justiça se torna uma discussão indispensável diante de um contexto no qual leis elaboradas e aplicadas a partir de perspectivas eminentemente punitivistas e estratégias de segurança pública baseadas no emprego da força física e da brutalidade coexistem com baixos índices de confiança nas instituições policiais e na justiça. A maior parte das pesquisas desenvolvidas até o momento no país a respeito do tema foram sediadas no Núcleo de Estudos da Violência da Universidade de São Paulo (NEv-UsP) e estabelecem um diálogo com a literatura da criminologia a respeito da legitimidade, com foco principalmente na legitimidade da polícia.

Com base em pesquisas de opinião conduzidas com os moradores da cidade de São Paulo, tais estudos têm encontrado, tal qual ocorre na literatura internacional, o efeito da percepção de justeza procedimental como principal preditor da legitimidade policial (Teixeira, 2019; Oliveira; Oliveira; Adorno, 2019; Oliveira, Zanetic \& Natal, 2020), indicando que, assim como ocorrem em outros países, a percepção de que a autoridade policial age de maneira justa e respeitosa é um elemento fundamental para o reconhecimento de sua legitimidade.

Essas pesquisas abordam a legitimidade como um constructo psicológico, ou seja, observando primordialmente a disposição de obedecer e o alinhamento normativo dos indivíduos. Especificamente sobre a mensuração do constructo de legitimidade, esses trabalhos têm adotado uma abordagem empírica, buscando identificar, por meio de questões abertas e fechadas, o que torna uma autoridade socialmente válida sob os olhos dos que estão submetidos. A questão da obediência voluntária, que tem sido um ponto-chave para desenredar a legitimidade de outras formas de submissão, foi trabalhada por meio de questôes abertas inseridas em surveys, inquirindo os entrevistados a respeito de suas razões para obedecer ou não às leis, às decisões 
judiciais e à polícia. Especificamente no caso da polícia ${ }^{15}$, os pesquisadores chegaram a uma categorização que congrega quatro tipos de respostas ${ }^{16}$. Em primeiro lugar, reafirmaram a obediência consensual, como aquela guiada por consentimento com a autoridade, composta por respostas que indicam o reconhecimento de um imperativo moral que leva ao dever de obedecer à polícia, refletindo o consentimento e a justificação do dever de obedecer a partir do respeito à lei e do dever de cidadania, como reconhecimento da autoridade do policial e do que ele representa em sua atuação profissional. Em segundo lugar, apontam a obediência por obrigação coercitiva, ou seja, pode estar fundada no medo da sanção ou coerção por parte da autoridade. Nesse caso as respostas indicam principalmente o medo das consequências (legais ou ilegais) da desobediência e da resignação pela impotência diante do poder da polícia. As outras categorias indicam limites à obediência, uma por protesto - por não concordar com a autoridade em situações em que consideram que os policiais estão agindo de maneira inapropriada - e a rejeição da autoridade - visão negativa da instituição, muitas vezes decorrente de percepções de desvios de comportamento e experiências negativas ${ }^{17}$ (Oliveira, Zanetic \& Natal, 2020).

Não é novidade que o medo da autoridade e o receio das possíveis consequências da desobediência são elementos importantes na discussão sobre legitimidade. $\mathrm{O}$ interessante é que as medidas e perguntas, largamente utilizadas pelos estudos conduzidos na literatura internacional, têm falhado em contemplar de maneira satisfatória esse aspecto na construção de legitimidade. Resta mais que evidente que a simples pergunta sobre a disposição de obedecer à polícia, mesmo quando discorda dela ou quando o policial está errado, não é uma boa questão para delimitar o consentimento. Se a obediência por medo de coerção é a antítese do que se espera como motivação em uma relação legitima, esse é um aspecto que deve, essencialmente, ser tratado pelos indicadores. O problema fica evidente quando, para além da obrigação por medo, os questionamentos da autoridade por protesto ou por total rejeição indicam um extenso rol de motivações e justificativas para o aceite/rejeição de seu exercício de poder.

Nessa direção, para além da questão das motivações instrumentais ou normativas, as reflexões de Weber sobre a legitimidade continuam fundamentais para os desdo-

15. Os entrevistados eram perguntados: "Acha que deve obedecer à polícia mesmo quando acredita que ela está errada?" Depois disso, eram instados a responder o porquê, responderam "sim" ou "não".

16. Partindo de tais categorias, os pesquisadores individualmente, analisaram e categorizaram todas as respostas abertas de acordo com suas compreensões. A taxa de concordância, ao final do processo, foi de aproximadamente $90 \%$.

17. De 1806 entrevistas, 1564 puderam ser categorizadas ( $86,6 \%$ do total). Dessas, 538 foram classificadas como obediência consensual (34,3\%), 106 como obediência coercitiva (6,7\%), 630 como desobediência por protesto (40,3\%), e 290 como desobediência por rejeição (18,5\%). 
bramentos das investigações sobre a legitimidade de instituições como a polícia e o judiciário. Isso principalmente porque as autoridades do campo da segurança pública e justiça, em sua atuação cotidiana, reproduzem valores de uma dada ordem social. No entanto, é importante lembrar que, para Weber, não há necessariamente uma única ordem operando. Não raras vezes, múltiplas ordens paralelas e contraditórias podem orientar as ações dos sujeitos, ao mesmo tempo. Se cada ordem social é válida na medida em que efetivamente tem a capacidade de orientar as ações dos envolvidos, os estudos sobre a legitimidade e sua operacionalização empírica, ainda que muito importantes para entender o quadro macro sobre as relações entre cidadãos e autoridades, nos parecem ainda insuficientes para pensar como a convivência entre diferentes sistemas normativos se dá e pode mesmo reforçar a existência das diferentes ordens. Neste caminho, as reflexões de Weber sobre a legitimidade podem continuar contribuindo com os estudos sobre a polícia e o sistema de justiça criminal.

Referências bibliográficas

BeCCARIa, Cesare. ([1764] 2016), On crimes and punishments. New Brunswick, NJ, Transaction Publishers.

BeCker, Gary. (1968), "Crime and punishment: an economic approach". Journal of Political Economy, 76 (2): 169-217.

Beetham, David. (1991a), The legitimation of power. Atlantic Highlands, NJ, Humanities Press International.

Beetham, David. (1991b), "Max Weber and the legitimacy of the modern state". Analyse \& Kritik, 13 (1): 34-45.

Beetham, David. (2011), “Legitimacy”. In: Badie, B.; Berg-Schlosser, D. \& Morlino, L. International encyclopedia of political science. Thousand Oaks, CA, Sage.

Beetham, David. (2013), "Revisiting legitimacy, twenty years on”. In: TAnkebe, J. \& LieBLING, A. (org.). Legitimacy and criminal justice: An international exploration. Oxford, UK, Oxford University Press, pp. 19-36.

Bentham, Jeremy. ([1871] 1996), An introduction to the principles of morals and legislation: The collected works of Jeremy Bentham. Oxford, Oxford University Press.

Bоттомs, Anthony \& Tankebe, Justice. (2012), "Beyond procedural justice: A dialogic approach to legitimacy in criminal justice". Journal of Criminal Law and Criminology, 102 (1): 119-170.

CaO, Liqun, \& Graham, Amanda. (2019), "The measurement of legitimacy: a rush to judgment?”. Asian Journal of Criminology, 14 (4): 291-299.

CoICAUd, Jean-Marc. (2002), Legitimacy and politics: a contribution to the study of political right and political responsibility. Cambridge, uk, Cambridge University Press. 
Faria, José Eduardo. (1978), Poder e legitimidade. São Paulo, Editora Perspectiva.

Hobbes, Thomas. ([1651] 1974), Leviatã. São Paulo, Abril Cultural. Coleção os Pensadores.

Hough, Mike et al. (2010), "Procedural justice, trust, and institutional legitimacy”. Policing: a Journal of Policy and Practice, 4 (3): 203-210. Dor: 10.1093/police/paq027.

Hough, Mike et al. (2012), "The governance of criminal justice, legitimacy and trust”. In: Body-Gendrot, S.; Lévy, R.; Hough, M.; Snacken, S.; Kerezsi, K. (eds.). The Routledge handbook of European Criminology. Oxford, UK, Routledge.

JACKson, Jonathan et al. (2012a), "Why do people comply with the law? Legitimacy and the influence of legal institutions". British journal of Criminology, 52 (6): 1051-1071.

JACKSON, Jonathan et al. (2012b), "Policing by consent: understanding the dynamics of police power and legitimacy. European Social Survey, Policing by consent: Understanding the dynamics of police power and legitimacy, ESS Country Specific Topline Results Series, n. 1.

JACKSON, Jonathan \& BRADFORD, Ben. (2019), "Blurring the distinction between empirical and normative legitimacy? A commentary on 'police legitimacy and citizen cooperation in China'”. Asian Journal of Criminology, 14: 265-289.

Kalberg, Stephen (org.). (2005), Max Weber: Readings and commentary on modernity. Malden, MA, Blackwell Publishing.

La BoÉtie, Etiene. ([1542] 1982), Discurso da servidão voluntária. São Paulo, Brasiliense.

Maquiavel, Nicolau. ([1532] 2010), O principe. Tradução de Maurício Santana Dias. São Paulo, Penguin Classics Companhia das Letras.

Netelenbos, Benno. (2016), Political legitimacy beyond Weber: An analytical framework. London, UK, Palgrave Macmillan.

Oliveira, Thiago et al. (2019), "Legitimidade policial: um modelo de mensuração”. Revista Brasileira de Ciências Sociais, 34.

Oliveira, Thiago; Zanetic, André \& Natal, Ariadne. (2020), "Preditores e impactos da legitimidade policial: testando a teoria da justeza procedimental em São Paulo”. Revista Dados, 63 (1): 1-40.

Paternoster, Raymond. (2010), "How much do we really know about criminal deterrence?". The Journal of Criminal Law and Criminology, 765-824.

Pierucci, Antônio Flávio. (2008), "Economia e sociedade: últimos achados sobre a 'grande obra' de Max Weber”. Revista Brasileira de Ciências Sociais, 23: 41-51.

Spencer, Martin. E. (1970), "Weber on legitimate norms and authority". The Britsh Journal of Sociology, 21 (2): 123-134.

Sun, Ivan Y et al. (2017), "Procedural justice, legitimacy, and public cooperation with police: Does Western wisdom hold in China?". Journal of Research in Crime and Delinquency, 54 (4): 454-478.

Sunshine, Jason \& Tyler, Tom R. (2003), “The role of procedural justice and legitimacy in shaping public support for policing”. Law \& Society Review, 37 (3): 513-548. 
Tankebe, Justice. (2008), Police effectiveness and police trustworthiness in Ghana: An empirical appraisal. Criminology \& Criminal Justice, v. 8, n. 2, p. 185-202.

TANKeBE, Justice. (2013), "Viewing things differently: The dimensions of public perceptions of police legitimacy: Public Perceptions of police legitimacy”. Criminology, 51 (1): 103-135.

Teixeira, Frederico Castelo Branco. (2019), Contato com a polícia e legitimidade policial na cidade de São Paulo. São Paulo, tese de doutorado, Faculdade de Filosofia, Letras e Ciências Humanas da Universidade de São Paulo.

Trinkner, Rick. (2019), "Clarifying the contours of the police legitimacy measurement debate: a response to Cao and Graham”. Asian Journal of Criminology, 14 (4): 309-335.

Tyler, Tom R. (2003), "Procedural justice, legitimacy, and the effective rule of law". Crime and Justice, 3: 283-357.

Tyler, Tom R. (2004), "Enhancing police legitimacy”. The Annals of the American Academy of Political and Social Science, 593 (1): 84-99.

Tyler, Tom R. (2006b), "Psychological perspectives on legitimacy and legitimation". Annual Review of Psychology, 57 (1): 375-400.

Tyler, Tom R. (2006a), Why people obey the law. Princeton, NJ, Princeton University Press.

Tyler, Tom R. \& Fagan, Jeffrey. (2010), “Legitimacy and cooperation”. In: Race, ethnicity, and policing. Nova York, University Press, pp. 84-117.

Tyler, Tom R. \& Huo, Yuen. (2002), Trust in the law: Encouraging public cooperation with the police and courts. Nova York, Russell Sage Foundation.

Walters, Glenn D. \& Bolger, P. Colin. (2019), "Procedural justice perceptions, legitimacy beliefs, and compliance with the law: A meta-analysis". Journal of experimental Criminology, 15 (3): 341-372.

Weber, Max. (1979), Sociologia. Tradução de Gabriel Cohn. São Paulo, Ática. Coleção Grandes Cientistas Sociais, n. 13.

Weber, Max. (1999a), Economia e sociedade: Fundamentos da Sociologia Compreensiva (volume 1). Brasília, Editora UnB.

Weber, Max. (1999b), Economia e sociedade: Fundamentos da Sociologia Compreensiva (volume 2). Brasília, Editora UnB.

Williams, Bernard. (2005), In the beginning was the deed: Realism and moralism in political argument. Princeton, NJ, Princeton University Press.

Wolfe, Scott et al. (2016), "Is the effect of procedural justice on police legitimacy invariant? Testing the generality of procedural justice and competing antecedents of legitimacy". Journal of Quantitative Criminology, 32 (2): 253-282.

Zanetic, André et al. (2016), "Legitimidade da polícia. Segurança pública para além da dissuasão". Civitas: Revista de Ciências Sociais, 16 (4): 148-173. 


\section{Resumo}

Legitimidade e obediência: diálogos da Criminologia com a Teoria sociológica

$\mathrm{O}$ artigo discute concepções de legitimidade e de obediência sugeridas por algumas abordagens da teoria social. Dispõe-se a problematizar perspectivas que examinam tais noções no âmbito de pesquisas sociológicas e criminológicas, com foco em análises de instituições de segurança e de justiça. Partindo dos escritos de Weber sobre ordens legítimas e os tipos de dominação, exploramos as propostas de operacionalização da legitimidade elaboradas por Beetham e Coicaud. Em seguida, introduzimos o debate de criminólogos contemporâneos como Tyler, Bottoms e Tankebe, que se focam na legitimidade das leis e da polícia. Por fim, discutimos os entraves para a mensuração da legitimidade e apresentamos solução adotada no contexto brasileiro.

Palavras-chave: Legitimidade; Obediência; Criminologia; Teoria social; Polícia.

\section{Abstract}

\section{Legitimacy and obedience: dialogues between Criminology and Social Theory}

The article discusses conceptions of legitimacy and obedience as suggested by some social theory approaches. It attempts to problematize perspectives that examine these notions within sociological and criminological research, focusing on analyses of security and justice institutions. Starting from Weber's writings on legitimate orders and the types of domination, we explore the proposals for operationalizing legitimacy elaborated by Beetham and Coicaud. Next, we introduce the debate of contemporary criminologists such as Tyler, Bottoms and Tankebe, who focus on the legitimacy of laws and the police. Finally, we discuss the obstacles to measuring legitimacy and present a solution adopted in the Brazilian context.

Keywords: Legitimacy; Obedience; Criminology; Social Theory; Police.

Texto recebido em 31/08/2021 e aprovado em 08/10/2021.

DOI: $10.11606 / 0103-2070 . t s .2021 .190229$

Ariadne Natal é doutora em Sociologia, pesquisadora de pós-doutorado do Peace Research Institute Frankfurt (PRIF) e pesquisadora associada do Núcleo de Estudos da Violência da Universidade de São Paulo (NEV-UsP).E-mail: natal@hsfk.de.

Frederico Castelo Branco é doutor em Ciência Política (USP) e pesquisador do NeV-USP. E-mail: fcastelo@gmail.com.

Marcos César Alvarez é doutor em Sociologia pela Universidade de São Paulo, com pós-doutorado na École des Hautes Études en Sciences Sociales, Paris, França. Professor do Departamento de Sociologia da USP e coordenador do NEV-USP.E-mail: mcalvarez@usp.br. 